\title{
Potential dangers of unlicensed daycares
}

$\mathrm{T}$ he death of two-year-old Eva Ravikovich brought national attention to the hazards and inconsistent oversight of unlicensed daycares in Canada.

"Unfortunately, it took a death to bring it to public consciousness," says Andrea Calver, coordinator of the Ontario Coalition for Better Child Care.

Eva died on July 8 in an unlicensed home daycare in Vaughan, Ontario. Though the exact cause of death is still unknown, authorities found expired and rotting food in the allegedly overcrowded daycare, including several items that contained Listeria. Other health hazards included kitchen utensils and toys that had not been properly disinfected.

Unbeknown to many parents, says Calver, there is very little oversight of unlicensed daycares in Ontario. "There's no food safety, there's no criminal background checks, there is absolutely nothing," she says. "Attila the Hun is welcome to look after five or fewer children in Ontario."

"Nothing surprises me in the unlicensed sector," adds Hillel Goelman, professor of early childhood education at the University of British Columbia in Vancouver. "They make their profit margin based on the number of kids they have, and they make their profit margin based on the fewer number of staff they have to pay to make sure that the kids are safe."

Potential health hazards in unlicensed daycares come in various forms. It could be a dangerous property feature that leads to accidents, such as steep stairs or an easily accessible radiator. In 2010, a two-year-old drowned in a pool at an unlicensed daycare in Orléans, Ontario. A child's health may also be compromised if the building has pets that aren't properly cleaned up after, notes Goelman, or if food preparation and dish-washing aren't performed hygienically.

Each province takes a different approach to monitoring and imposing restrictions on unlicensed daycares. The maximum number of children allowed in such a facility, for example, varies across the country.

In Ontario, the Day Nurseries Act

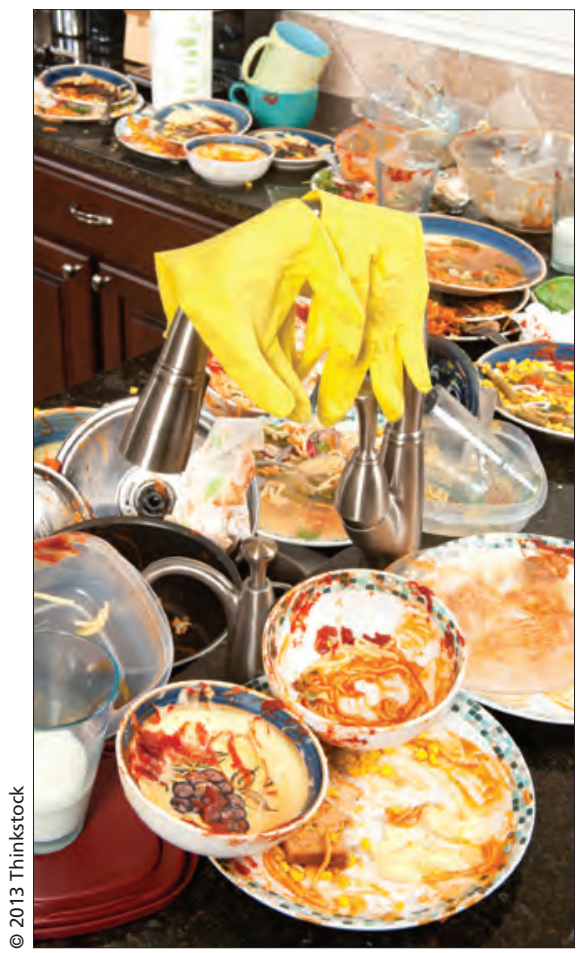

The risks to children's health of unhygienic conditions in unlicensed home daycares received national attention following the death of an Ontario toddler in a daycare that contained expired and rotting food, including several items with Listeria.

states that a person may provide unlicensed care to five or fewer children under age 10 , in addition to their own children. But the Ontario Ministry of Education doesn't track or monitor these facilities and can only initiate an inspection after a complaint, according to ministry spokesperson Gary Wheeler.

The ministry receives 200-300 complaints a year, adds Wheeler, and has a policy to conduct one or more unannounced follow-up visits when a provider is found to be out of compliance with the Day Nurseries Act. Following the death of Eva Ravikovich, Ontario Ombudsman André Marin announced in a press release that he would be conducting an investigation into the ways the ministry responds to complaints.

In Alberta, an unlicensed daycare can host up to six children. In Manitoba, a person can provide private home childcare without a licence to a maximum of four children under age 12 . Yet, like Ontario, the province does not independently monitor unlicensed facilities. It relies entirely on complaints, of which it receives about 50 a year.

British Columbia has more stringent rules, requiring a licence for daycare operators looking after more than two children. In Nova Scotia the number climbs to six children of any age or eight school-aged children.

Although the number of children allowed in these facilities varies, some things are fairly consistent, such as poor record-keeping of health hazards and little awareness among parents of the rules for unlicensed daycares.

"There's a huge amount of confusion about what's legal, what's not legal. I think it's entirely plausible [that parents could] have their children in an unlicensed home environment without really knowing that there's actually no oversight whatsoever," says Calver.

More needs to be done by provincial governments to provide high-quality, affordable daycare so parents don't have to resort to unlicensed home daycares, says Calver. "The problem is there's not enough childcare," she says. "For the vast majority of families, it's simply not an option. It is either too expensive or the waiting list is too long.'

If parents do choose an unlicensed facility, they should check if it is connected to a professional association and if staff are properly supervised and linked to other caregivers, because an isolated unlicensed daycare is "a recipe for disaster," says Goelman.

"I think parents really have to do their due diligence to ask many kinds of questions," he says, adding that there are quality checklists and guidelines available online in many provinces.

"As long as we have people operating under the radar, we run the risk of children being hurt and worse." Adam Miller, Toronto, Ont.

CMAJ 2013. DOI:10.1503/cmaj.109-4643

\section{More News online}

To read more CMAJ news articles, visit cmaj.ca/site/home/news.xhtml 